\title{
Soil Determination using PH - Nutrient Relatively
}

\author{
Bharati Masram, Harsh Mehta, Harshal Bokade, Hritik Jain, Shrawani Wankhede
}

\begin{abstract}
INDIA, an agriculture-based country where the economy is dependent on agriculture and climatic conditions. Primary reason of this project is to fulfil the needs of farming quality by reducing excessive fertilizer abuse by controlling some parameters. So, the parameters are temperature, moisture, light, Ph through which we can identify the suitable crop and its nutrition level. Our project uses 3 types of sensors to increase productivity of the crops. Soil testing for productivity is taken by proposal of supplements needs. We are using Arduino UNO with the sensors.

Determining the $\mathrm{pH}$ of soil is one of the key parameters for improving crop quality so the amount of the amount of fertilizer used is adequate and not excessive for the crops. Other main sensors used are light and hygrometer sensors. We can classify plants based on their light needs like high, medium or low. So, the light received by the crops depends upon the nearness of light. We should adequately address spatial variation for crop productivity when we consider $\mathrm{pH}$ to rejuvenate agriculture.
\end{abstract}

Keywords: FERTILITY OF SOIL, NPK, REAL TIME DETECTION, PH RANGE FOR CROPS.

\section{INTRODUCTION}

Interaction between plant properties and soil properties shows the production of crops. To get maximum production of crops depends upon biological, chemical, the physical content of the soil which shows the biochemical reaction. If the supply of nutrients is not sufficient crop production affects[1]. Plants require some nutrients in more quantity so-called macronutrients.

Fertilizers should be properly distributed considering the production of crops. The harvest rate of production can be reduced if fertilizer is under-provisioned still there is a huge

Revised Manuscript Received on April 21, 2020.

* Correspondence Author

Bharati Masram*, Department of Electronics \& Telecommunication Yeshwantrao Chavan College of Engineering Nagpur, India.Email: bharatimasram@gmail.com

Harsh Mehta, Department of Electronics \& Telecommunication Yeshwantrao Chavan College of Engineering Nagpur, India.Email: hmehta199495@gmail.com

Harshal Bokade, Department of Electronics \& Telecommunication Yeshwantrao Chavan College of Engineering Nagpur, India. Email: harshalbokade03@gmail.com

Hritik Jain, Department of Electronics \& Telecommunication Yeshwantrao Chavan College of Engineering Nagpur, India. Email: hritikjain79@gmail.com@gmail.com

Shrawani Wankhede, Department of Electronics \& TelecommunicationYeshwantrao Chavan College of Engineering Nagpur, India. Email: shravaniwankhede441997@gmail.com

(C) The Authors. Published by Blue Eyes Intelligence Engineering and Sciences Publication (BEIESP). This is an open access article under the CC BY-NC-ND license (http://creativecommons.org/licenses/by-nc-nd/4.0/) demand for crops. So, traditionally the farming condition and cultivation decided the rate of production. Still the increasing demand for the population is the main crisis. If we don't use fertilizers properly then it may lead to consequences like small vegetable size, poor quality fruits, taste, quality as well as quantity.

To improvise in agriculture its time for us to embark on new technology and implement them. Our project will ensure this objective, also the project will set the limits on the high manufacturing rate of technological projects as the product can be readily made \& easily available to farmers at minimal cost[8].

So, the economy will also be benefited as the productivity will increase ultimately leading to improvement in our farmer lifestyle and new technologies may become affordable for farmers[9].

\section{Problem Definition}

Increased suicide rates are a shame to the nation and it is a matter of concern and needs to be reduced. Food \& eatables available in the market are not as nutritious as they used to be, this is leading to many foods borne diseases and needs to be looked over[3].

To design a system i.e. well suited to perform various operations and to find out the parameters like $\mathrm{pH}$, Moisture, light ultimately leading to determine which crop to cultivate. We are using three sensors Technology, Microcontroller Technology \& serial communication Technology.

\section{MethodologY}

In this project we will need three technologies and by combining these three technologies we will achieve our desired result.

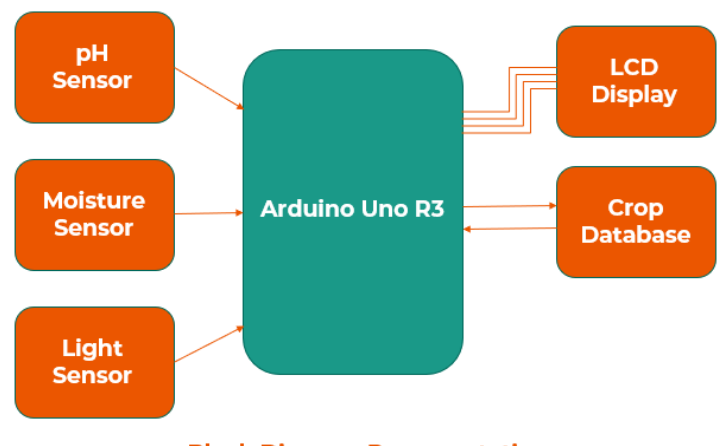

Fig. 1.Block Diagram.

The concepts using are as follows: -

\section{Published By:}

Blue Eyes Intelligence Engineering

\& Sciences Publication 


\section{A. Sensor Technology:}

Several sensing technologies are used in precision agriculture, providing data that helps farmers monitor and optimize crops, as well as to adapt to changing environmental factors including.

The sensors that will be used are pH Sensors, Light Sensors, and Hygrometer Sensors. They will provide input to the Microcontroller.

Soil pH can control how well your crops grow better. The balance of acid-forming nutrients and alkaline-forming nutrients can influence root development, microbial activity, fungi, symbiotic nitrogen fixation by legumes and the availability of nutrients. $\mathrm{pH}$ sensor enables you to monitor $\mathrm{pH}$ levels to ensure an ideal $\mathrm{pH}$ is maintained[4].

The intelligent agriculture techniques mean using the sensor system to control the light intensity. The light sensor is an electronic device that is used to detect the presence or non-presence of light and darkness.

Plants can be classified according to their light needs, such as high, medium and low light requirements. Thus, it is important to use a light sensor to analyze the growth of plants. The light intensity received by an indoor plant depends upon the nearness of the light source to the plant [2]. Light intensity rapidly decreases as the distance from the light source increases.

\section{B. Microcontroller Technology}

The Arduino Uno R3 will play the role of the Microcontroller involved in this project. It will take input from the sensors and analyze the data to give the output at an LCD screen serially.

\section{Serial Communication Technology}

The Output of the Arduino Uno Processed data will be serially transmitted to a Display Device such as an LCD/OLED.

\section{BLOCK DIAGRAM DESCRIPTION}

The Crop Determination system consists of BH1750 Light sensor, $\mathrm{pH}$ sensor, Electrochemical sensor, as shown in Fig 2,3 and 4. Arduino UNO ReV3 USART microchip as shown in Fig 5, with this we also need LCD display to display the result and also some connectors .

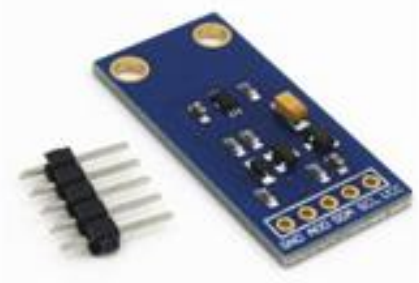

Fig. 2.Light Sensor.

This sensor will sense and calculate the intensity of ambient light. It is a passive device that converts light energy in visible or infrared parts of spectrum into electrical signal output.

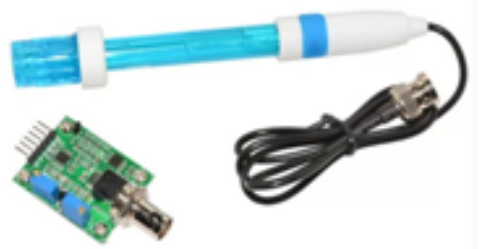

Fig. 3.pH sensor.

This Sensor will sense the $\mathrm{pH}$ of soil determining the NPK rates considering $\mathrm{pH}$ - nutrients relativity index. It is specially designed for Arduino \& other Microcontroller. It uses an industry electrode and it has LED which works as a power indicator, BNC connector and $\mathrm{pH}$ sensor interface. It indicates measurement of $\mathrm{H}^{+}$ions in the soil[5]

The sensor we used has a $\mathrm{pH}$ electrode made of sensitive glass membrane with low impedance for the project to be reasonable for more durability steel tip $\mathrm{pH}$ sensor can be used.

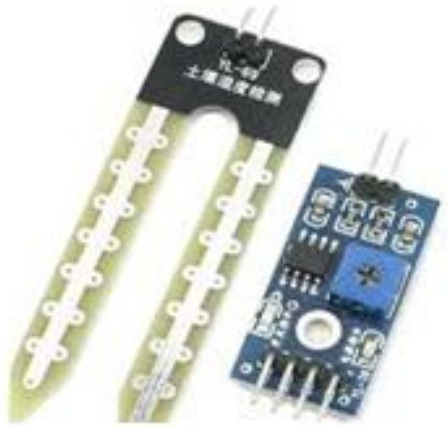

Fig. 4.Electrocheical sensor.

Soil Electrochemical Moisture sensor[6] will sense the moisture content of the soil is adequate or not.It has a two cathode chips attached to each other. Electrochemical sensor identifies the chemical changes in the form $\mathrm{H}+\& \mathrm{OH}$ - ions. This ultimately helps in the determination of moisture content of soil. The sensor needs to be tackled properly as it is easily damaged soil testing.

\section{A. Arduino UNO ReV3}

This runs on the ATMEGA A628 Microcontroller chip having an enhanced $16 \mathrm{MHz}$ oscillator ARDUINO ISP and programmer. Input voltage of Arduino is $7-12 \mathrm{v}$ and its working voltage is $5 \mathrm{v}$. Storage stats are $23 \mathrm{~KB}$ flash memory, 2KB SRAM \& 1 KB EPROM, which are enough for implementation of our idea cheaply and conveniently.[7]

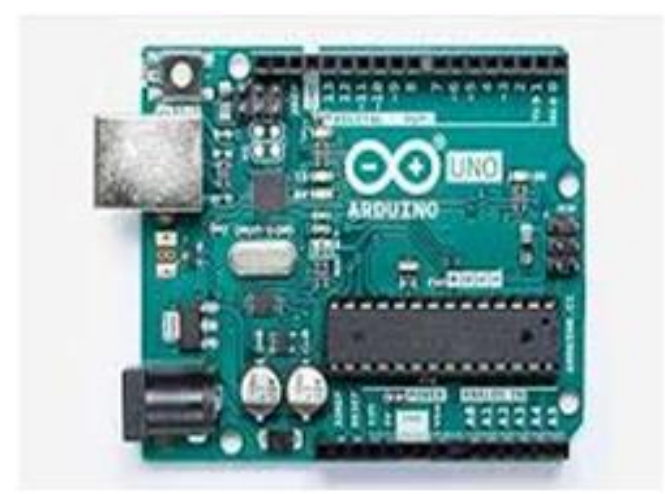

Fig. 5.Arduino Uno ReV3

Published By:

Blue Eyes Intelligence Engineering

\& Sciences Publication

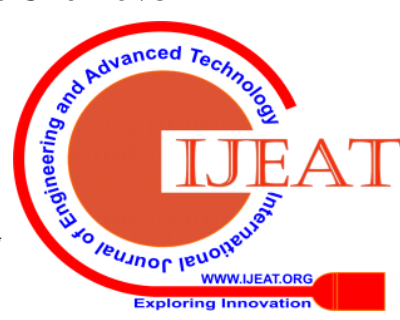




\section{USART MICROCHIP}

This enables serial communication of Arduino Board though RS - 232C Portal. There is an additional synchronous communication mode of the USART chip which enables high Baud Rates along with high Data Transfer Rate (DTR).

\section{EXPERIMENTAL SET UP \& ITS RESULTS}

Experimental Set up as shown in Fig 6, Output display shows the amount of light, $\mathrm{pH}$, Moisture the soil comprises, also determines the nutrients level of the soil sample and recommends which seeds to grow as shown in Fig 8,9 respectively. The $\mathrm{pH}$ range in the given Table I are the results of our proposed circuit, which are calibrated accordingly to the code.

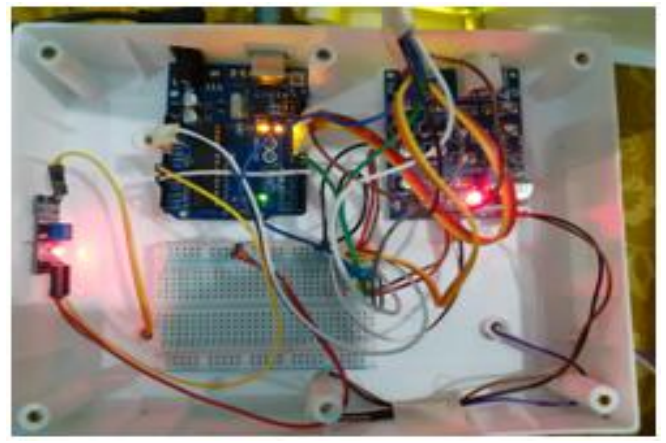

Fig . 6. Experimental setup of Crop (Soil) Buddy As given below in the table I are the outputs of Analog to Digital convertor i.e. connected to $\mathrm{pH}$ sensor. These values are mapped to a particular $\mathrm{pH}$ value range suitable for the crop to grow. For the data purpose we have just taken the examples sample soil for Orange and Cotton crop .

Table- I: Values for Different Soil

\begin{tabular}{|c|l|c|c|c|}
\hline $\begin{array}{c}\text { Sr. } \\
\text { No. }\end{array}$ & $\begin{array}{c}\text { Soil Used } \\
\text { for sample }\end{array}$ & $\begin{array}{c}\text { Required } \\
\text { pH range }\end{array}$ & $\begin{array}{c}\text { Recorded } \\
\text { pH Value }\end{array}$ & $\begin{array}{c}\text { Moisture } \\
\text { Value range }\end{array}$ \\
\hline 1. & Orange & $180-220$ & 209 & $880-930$ \\
\hline 2. & Cotton & $355-383$ & 356 & $830-920$ \\
\hline
\end{tabular}

The values from the table given below are compared with the recorded values, if the value is suitable to cotton soil then the cotton crop can be grown.

\section{A. pH Value for Orange Soil}

The $\mathrm{pH}$ value for the orange soil is recorded as 209 as shown in Fig. 7. display of LCD in our experimental set-up.

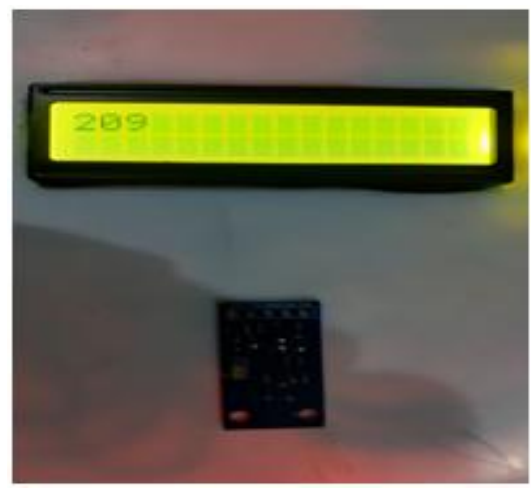

Fig. 7. Recorded pH value for orange

\section{B. pH Value for Cotton Soil}

The $\mathrm{pH}$ value for the Cotton soil is recorded as 356 as shown in Fig. 8. display of LCD in our experimental set-up.

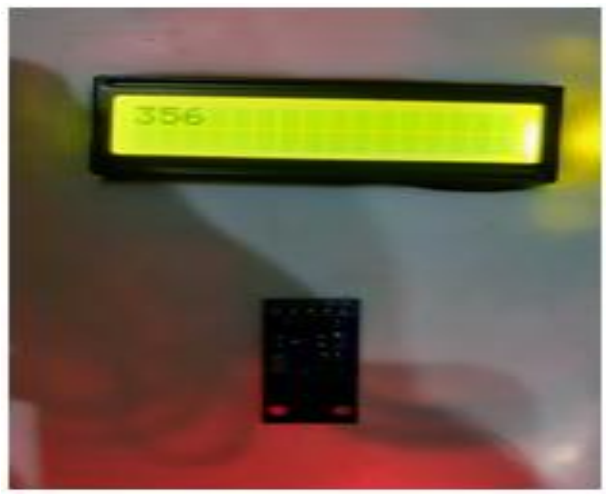

Fig. 8. Recorded pH value for cotton

The values from the Table- I are compared with the recorded value given in the fig. 7 and 8 , if the value is suitable to the range then it displays as shown in Fig. 9.
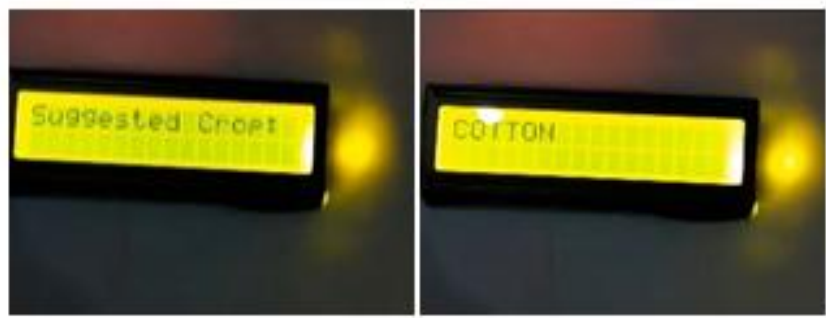

Fig.9. Display Result

\section{CONCLUSION}

In this paper , we have designed a complete setup of crop determination using sensor-based technology for two crops ie for Orange and Cotton. The soil sensor has resulted in the determination of two different soil conditions along with the amount of nutrition they provide and also the soil sample which will show various qualities of crops. As the database can be manually updated whenever we want, therefore, the setup is more usable depending upon the suggested availability. Engineering being advanced has started various soil testing techniques like the KISS (Keep It Basic and Stupid) principle to tackle difficult soil testing methods using cheap and effective methods in future.

This device works at a very cheaper rate compared to other things that are available in the market.

\section{REFERENCES}

1. R.Sindhuja and B.Krithiga "Soil Nutrient Identification Using Arduino" in Asian Journal of Applied Science and Technology (AJAST) Volume 1, Issue 4, Pages 40-42, May 2017.

2. C. M. A. Brett and A. M. Oliveira Brett, Electrochemistry, Principles, Methods and Application Chap. 10, Oxford University Press, Oxford (1993)

3. C. Jones and J. Jacobsen, "Plant Nutrition and Soil Fertility", in Nutrien Management Modules, No. 2, 2014.

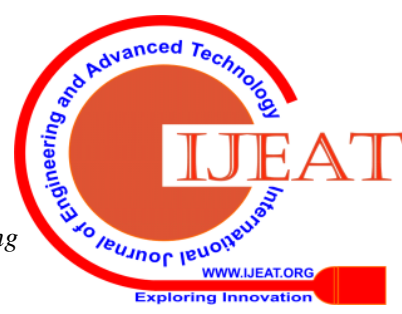


4. G. Dharesh Vadalia, Minal Vaity, Krutika Tawate, Dynaneshwar Kapse, "Real Time soil fertility analyzer and crop prediction," in Proc. IRJET, 2017, pg. 2395-0072

5. Mr. Gaikwad S. V, Prof. Galande S. G, "Measurement of NPK, Temperature, Moisture, Humidity using WSN" in Proc. IJERA., 2015, pg. 84-89

6. A. Salve and S. Sagar, "Soil Nutrient Identification" in Proc. IRJET, 2018, pg. $1327-1328$.

7. N. V. Hue, R. Uchida, M. C. Ho, "Sampling and Analysis of Plants and Soil Tissues, How to take representative samples, How the samples are tested", in Plant Nutrient Management in Hawaii soils, Approaches for Tropical and Sub-tropical Agriculture, 2014.

8. A Survey on Soil Testing, http://www.vegetablegardener.com/item/2374/soil-testing-savvy.

9. Instructable "Arduino Soil Moisture Sensor" by 'goks_lf'.https://www.instructables.com/id/ARDUINO-PH-METER/

\section{AUTHORS PROFILE}

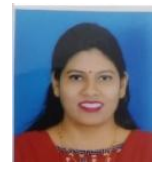

Bharati Masram has received her Ph.D in Electronics Engineering from Yeshwantrao Chavan College of Engineering (Autonomous) as research centre in 2020.She is currently working as Asst. professor in Department of Electronics \& Telecommunication Engineering, YCCE, RTM Nagpur University, India. Her research interest is mainly in VLSI Signal Processing, Communication; 3D Image processing etc .She has published her total 12 research based papers in national, international conferences and also in International scopus journal. She had also published one patent on Wireless apparatus in 2018.

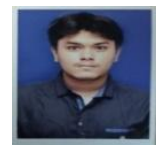

Harsh Mehta is pursuing a bachelor's degree in Electronics \& telecommunication from Yeshwantrao Chavan College of Engineering Nagpur, Maharashtra, India

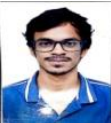

Hritik Jain is pursuing a bachelor's degree in Electronics \& telecommunication from Yeshwantrao Chavan College of Engineering Nagpur, Maharashtra, India

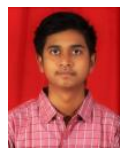

Harshal Bokade is pursuing a bachelor's degree in Electronics \& telecommunication from Yeshwantrao Chavan College of Engineering Nagpur, Maharashtra, India

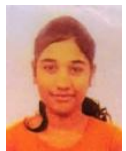

Shrawani Wankhede is pursuing a bachelor's degree in Electronics \& telecommunication from Yeshwantrao Chavan College of Engineering Nagpur, Maharashtra, India.

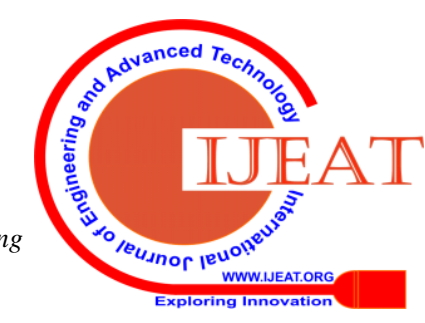

